\title{
Techno-economic assessment of common reed and sewage sludge co-fermentation improved by vapothermal pre-treatment
}

\author{
Marvin Scherzinger $^{1}$ (D) Marvin Kaltschmitt $^{1}$
}

Received: 9 June 2021 / Accepted: 18 August 2021 / Published online: 27 August 2021

(c) The Author(s) 2021

\begin{abstract}
This study examines whether vapothermal pre-treatment is technically feasible and brings economic advantages for a subsequent anaerobic co-fermentation of reeds together with sewage sludge. This is illustrated by the example of remote sites located close to constructed wetlands in the Persian Gulf states. Thus, eight different biogas plant configurations with an installed electric power between 75 and $450 \mathrm{~kW}$, each with and without vapothermal pre-treatment, are investigated in detail related to technical and economic figures. Within the technical assessment, suitable plant components are chosen and overall plant layouts are designed and dimensioned. Furthermore, the requirements on the substrate by means of quantity, pre-treatment and storage capacities are investigated. Based on this, an economic evaluation following the annuity method is performed in order to calculate the respective electricity production costs. The results show that the thermal energy required for vapothermal pre-treatment can be obtained completely from the residual heat of the combined heat and power unit used in each case. Additionally, the specific electricity production costs can be reduced by a vapothermal pre-treatment up to $7 \%$ related to the systems without pre-treatment. Furthermore, a comparison shows that vapothermal pre-treatment can compete with other pre-treatment methods such as steam explosion and hydrothermal pre-treatment for plants with higher installed electric capacity. In addition, it is shown that the considered cases can compete with the production of electricity using diesel as a fuel at a fuel equivalent price of $1.00 €$
\end{abstract}

\section{Graphic abstract}

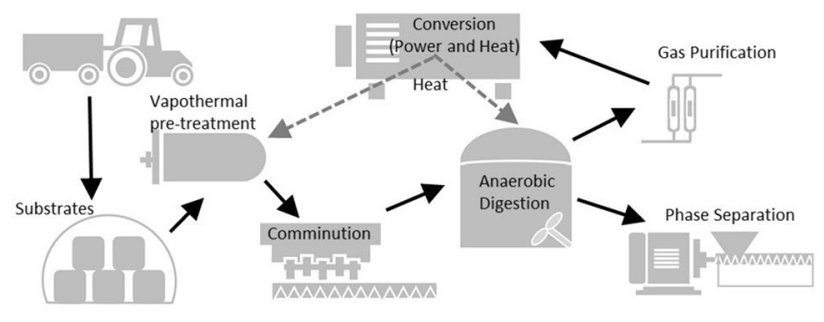

Keywords Biogas $\cdot$ Co-fermentation $\cdot$ Vapothermal pre-treatment $\cdot$ Energy system design $\cdot$ Cost accounting

Marvin Scherzinger

marvin.scherzinger@tuhh.de

1 Institute of Environmental Technology and Energy Economics (IUE), Hamburg University of Technology (TUHH), Eissendorfer Strasse 40, 21073 Hamburg, Germany

\section{Introduction}

Despite all efforts to achieve defossilation in order to mitigate anthropogenic climate change, the level of crude oil production was at an all-time high with an average production of around 95.2 million barrels per day in 2019 (BP p.I.c. 2020). Even if the substitution of crude oil based petroleum is progressing strongly, it seems not realistic that its production will end within the next two to maximal three decades as requested based on the valid GHG reduction goals defined 
within the Paris Agreement, as many parts of our globalized industrial sector are still heavily dependent on it. Therefore, the production of crude oil realized within different production phases will continue in the years to come. Nevertheless, due to the slow exhaustion over time of the well-known crude oil resources under production, more and more water is produced from these reservoirs; e.g. in some crude oil reservoirs already $99 \%$ water and only $1 \%$ oil is produced (Neukirchen and Ries 2016).

Subsequent to the extraction of such an oil-water emulsion carried from the underground, the oil phase must be separated from the water phase (e.g. using phase separators) to allow for a further processing of the crude oil to products marketable to the final customer. The remaining wastewater usually still contains crude oil components and is therefore harmful to the environment. For instance due to techno-economic constraints given during separation, the residual oil content sums up typically to around $500 \mathrm{ppm}$ oil in this wastewater prohibiting a subsequent disposal. Thus, this wastewater is often pressed back into the crude oil reservoir to contribute to the respective pressure level and to help maintaining the mass balance. But, this procedure requires a lot of energy and it is not always necessary from a reservoir engineering point of view (Baeuerle 2012).

A possible alternative is the treatment of this wastewater within constructed wetlands. The wastewater purification thereby relies on the combined action of the used wetland plants (hydrophytes), naturally occurring microorganisms and aggregate materials. Usually, the investment costs for constructed wetlands are clearly lower compared to conventional wastewater treatment plants and the costs for operation are very low since the water flow through plant beds is typically realized by gravity. Nevertheless, the hydrophytes have to be pruned at regular intervals in order to ensure a continuous and undisturbed water flow. Furthermore, the space required for such plants is much larger compared to conventional wastewater treatment plants (Stefanakis et al. 2014).

In the Persian Gulf states, high space requirements are typically no problem in onshore production of crude oil since desert areas are predominantly very scarcely populated. Nevertheless, if such a constructed wetland will be erected and operated at a specific site, a concept is needed to use or dispose the hydrophytes residues. Another factor to consider at such a remote location in the desert is the power supply. Due to a site typically far away from a well-developed infrastructure, a connection to the public power grid is not necessarily guaranteed at such remote sites. Instead, electricity is often produced by diesel generators.

Against this background, this publication examines selected techno-economic criteria of an electricity production from biogas provided from the anaerobic digestion of above ground reed biomass from a constructed wetland. Due to the C:H:N:S ratio of common reed being unfavourable for an exclusive anaerobic digestion (Roj-Rojewski et al. 2019), a co-fermentation with sewage sludge coming from the wastewater treatment plant of a nearby container village for oil workers is assumed. As common reed has a relatively low biogas formation potential due to its high amount of recalcitrant substances such as lignin, a vapothermal pretreatment step is also included in this study. The effects of such a pre-treatment on the biogas yield have extensively been assessed, e.g. on the example of wheat straw (Rajput et al. 2018). During such a pre-treatment, a solubilisation of thermal unstable organic constituents and a change in the structural composition of the organic matter takes place, allowing for an easier conversion into biogas during the subsequent anaerobic digestion (Scherzinger and Kaltschmitt 2021). Thus, one aspect is to show whether such a pre-treatment can also be advantageous from an economic point of view.

Currently, there are only few publications on this topic available. However, one study demonstrated that a low temperature thermal pre-treatment (i.e. $<100{ }^{\circ} \mathrm{C}$ ) could have a positive impact on the energy production costs in the anaerobic digestion of sewage sludge (Mirmasoumi et al. 2018). Furthermore, positive economic effects were achieved when applying steam explosion pre-treatment before anaerobic digestion of wheat straw and paper tube residuals (Shafiei et al. 2013). With regard to the severity of reaction parameters such as temperature and pressure, the vapothermal pretreatment process considered in the present study can be classified between the earlier mentioned processes (i.e. low temperature thermal pre-treatment and steam explosion pretreatment). Other studies dealing with vapothermal or similar pre-treatment to enhance anaerobic degradability of lignocellulosic biomass highlight the urgent need for research concerning the implementation of such pre-treatment techniques in a larger scale (Rajput et al. 2018).

In order to close this gap, in this study first a biogas plant is designed both with and without vapothermal pre-treatment. Then, different cases are examined, differing regarding the installed power. The specific electricity production costs are determined by means of annuity-based cost accounting and compared to electricity provision costs for decentral production via fossil fuel energy. Furthermore, vapothermal pre-treatment is compared with other pre-treatment technologies in order to determine its economic competitiveness.

\section{Material and methods}

\section{Design of the biogas system}

In this study, four different size classes of biogas plants with an electric power output of 75, 160, 360 and $450 \mathrm{~kW}$, 
respectively, are considered. These size classes were selected based on the product spectrum of a CHP manufacturer (2G Energy AG 2020) and are typically representative for small and medium-sized biogas plants. For each size class, two different biogas plants are investigated: one realizing cofermentation of untreated reeds with sewage sludge and one realizing co-fermentation of vapothermal pre-treated reeds with sewage sludge (Table 1). The ratio between reed and sewage sludge (based on dry matter) is 3 to 1 .

The characteristics of the substrates assumed here are shown in Table 2. Data for untreated reeds and sewage sludge originate from a previous study (Scherzinger et al. 2021), data from literature (Qiao et al. 2011) and unpublished investigations performed by the authors of this study. Results for pre-treated reeds are obtained assuming an increase of $20 \%$ in biogas respectively methane yield. This assumption is considered conservative, as in different studies even higher additional yields were achieved for similar lignocellulosic substrates (e.g. (Menardo et al. 2012)). However, the possible additional yield depends strongly on the composition of the initial biomass, which is why different results can be achieved even for plants of the same species (Scherzinger and Kaltschmitt 2021).

Among different wetland plant species, Phragmites australis investigated here is known as the most promising potential biogas substrate due to its high aboveground biomass yield and the resulting high methane production per area (Roj-Rojewski et al. 2019).

In order to design a biogas system to convert the aforementioned substrates into usable energy, suitable plant components are chosen and dimensioned. The basic plant setup shown in Fig. 1 differs only in the pre-treatment and is the same apart from that. Furthermore, the requirements on the substrate by means of quantity, pre-treatment and storage capacities are investigated. The need for auxiliary materials as well as the respective heat demand are evaluated additionally. This overarching approach of this study is illustrated in Fig. 2. The underlying assumptions are explained in more detail below.

The input materials are transported to the biogas plant with a tractor and trailer. Before this input material is transferred into the digestion system, it is stored on site of the biogas plant. For this purpose, simple driving silos consisting of a concrete floor slab were designed with the following specifications.

- The size for the reed storage is sufficient to store ca. 50 $\%$ of reeds needed in each plant in one year. The reeds are delivered as bales with a bulk density of $200 \mathrm{~kg} \mathrm{~m}^{-3}$ (Granéli 1984). The stacking height is $5 \mathrm{~m}$.

- Sewage sludge is available continuously in the form of dried material due to the dry and hot climate. Therefore, the sludge storage is designed to be sufficient for the storage of the needed input material for 14 days or two weeks. The bulk density of dried sewage sludge is 1,600 $\mathrm{kg} \mathrm{m}^{-3}$ (Duennebeil 2021). The stacking height is again $5 \mathrm{~m}$.

A vapothermal pre-treatment of the reed can be realized before the introduction into the digestion system. In cases applying vapothermal pre-treatment, a cylindrical reactor with the same size is used (diameter $2 \mathrm{~m}$; length $10 \mathrm{~m}$ in Case I and II and $20 \mathrm{~m}$ in Case III and IV; width $6 \mathrm{~mm}$ ). This reactor was designed to meet the requirements for temperature and pressure, i.e. $150{ }^{\circ} \mathrm{C}$ and $4.8 \mathrm{bar}$, respectively. Such reactors are already available on the market, e.g. for vapothermal carbonization (Quicker and Weber 2016). The calculation of the necessary reactor thickness was carried out according to Equation 1, where stainless steel (Type 304) was assumed as reactor material. The needed key data were taken from the literature (Towler and Sinnot 2013).
Table 1 Cases considered within the techno-economic assessment

\begin{tabular}{|c|c|c|c|c|c|c|c|c|}
\hline & \multicolumn{2}{|l|}{ Case I } & \multicolumn{2}{|l|}{ Case II } & \multicolumn{2}{|l|}{ Case III } & \multicolumn{2}{|l|}{ Case IV } \\
\hline & $\mathrm{a}$ & $\mathrm{b}$ & $\mathrm{a}$ & $\mathrm{b}$ & $\mathrm{a}$ & $\mathrm{b}$ & $\mathrm{a}$ & $\mathrm{b}$ \\
\hline $\begin{array}{l}\text { Installed electric power } \\
\text { Vapothermal pre-treatment }\end{array}$ & $\begin{array}{l}75 \mathrm{~kW} \\
\text { no }\end{array}$ & $\begin{array}{l}75 \mathrm{~kW} \\
\text { yes }\end{array}$ & $\begin{array}{l}160 \mathrm{~kW} \\
\text { no }\end{array}$ & $\begin{array}{l}160 \mathrm{~kW} \\
\text { yes }\end{array}$ & $\begin{array}{l}360 \mathrm{~kW} \\
\text { no }\end{array}$ & $\begin{array}{l}360 \mathrm{~kW} \\
\text { yes }\end{array}$ & $\begin{array}{l}450 \mathrm{~kW} \\
\text { no }\end{array}$ & $\begin{array}{l}450 \mathrm{~kW} \\
\text { yes }\end{array}$ \\
\hline
\end{tabular}

Table 2 Substrate characteristics

\begin{tabular}{|c|c|c|c|c|}
\hline Input material & $\begin{array}{l}\text { Dry matter (DM) content in } \\
\text { wt } \% \text { of fresh mass (FM) }\end{array}$ & $\begin{array}{l}\text { Organic matter }(\mathrm{OM}) \text { content } \\
\text { in wt } \% \text { of dry matter }\end{array}$ & $\begin{array}{l}\text { Biogas yield in } \\
\mathrm{L}_{\mathrm{N}} \mathrm{kg}_{\mathrm{VS}}{ }^{-1}\end{array}$ & $\begin{array}{l}\text { Methane } \\
\text { yield in } \\
\mathrm{L}_{\mathrm{N}} \mathrm{kg}_{\mathrm{VS}}{ }^{-1}\end{array}$ \\
\hline Reeds (Phragmites australis) & 94.0 & 95.4 & 220 & 110 \\
\hline Reeds after vapothermal pre-treatment & 94.0 & 95.0 & 264 & 132 \\
\hline Sewage sludge & 94.4 & 67.3 & 410 & 205 \\
\hline
\end{tabular}


Fig. 1 Schematic setup and balance limits of the investigated biogas plants
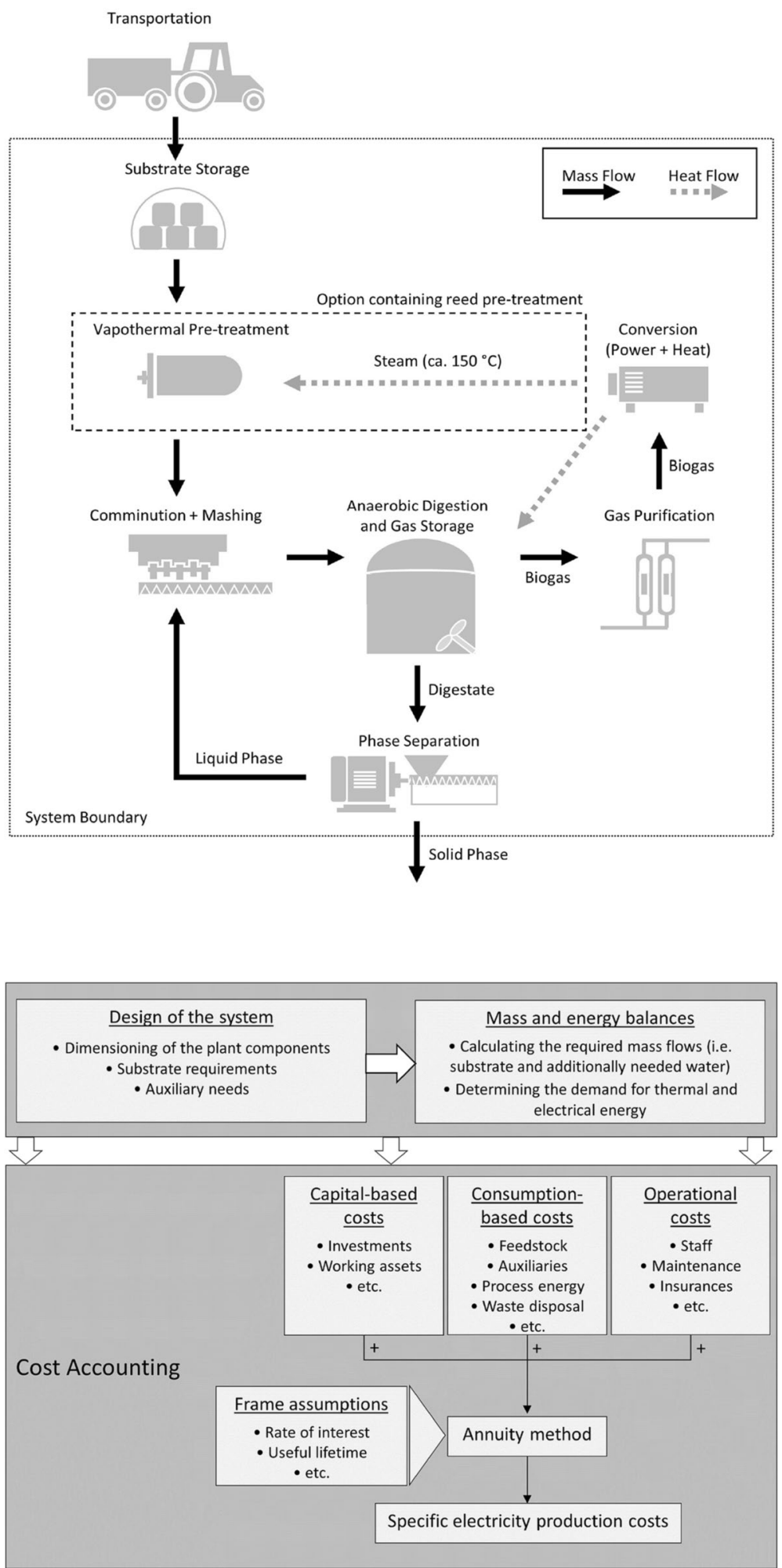

Fig. 2 Methodological procedure of the techno-economic assessment

$$
t=\frac{P_{i} D_{i}}{2 S E-1.2 P_{i}}
$$

$t$ is the minimum thickness required, $P_{i}$ is the internal pressure, $D_{i}$ is the internal diameter, $\mathrm{S}$ is the maximum allowable stress at $150{ }^{\circ} \mathrm{C}$ and $\mathrm{E}$ is the welded joint efficiency.

Previous investigations showed that in this temperature range (i.e. $130-150{ }^{\circ} \mathrm{C}$ ), the highest increase in anaerobic 
digestibility of common reed could be achieved (Scherzinger et al. 2021). In each batch, 8 (Case I and II) or 16 (Case III and IV) round bales (Diameter $=1.8 \mathrm{~m}$; Length $=1.2 \mathrm{~m}$ ) can be pre-treated. As a result, the vapothermal pre-treatment assumed to be a batch process is carried out more frequently for the larger size classes (with the same equipment). Furthermore, in all considered cases, the reed material has to be comminute. For this purpose, a wet milling system with a maximum input capacity of $25 \mathrm{th}^{-1}$ is used, in which the substrate is simultaneously crushed and mashed to the desired water content (Kratky and Jirout 2011). Here, $1 \mathrm{~kg}$ dry matter has to be mixed with $10 \mathrm{~kg}$ water to receive a pumpable mixture.

Biogas is produced in a fully stirred fermenter. Mixing within the digester is carried out with electrically operated propeller agitators. A relatively short hydraulic retention time of 25 days is assumed and the digestion takes place at mesophilic conditions (i.e. $37^{\circ} \mathrm{C}$ ). The fermenter sizes were calculated by multiplying the amount of substrate input (density of the mashed substrate $=1,000 \mathrm{~kg} \mathrm{~m}^{-3}$ ) needed to produce the required quantity of gas with the chosen hydraulic retention time.

The provision of heat for ensuring mesophilic conditions in the fermenter as well as for vapothermal pretreatment should be covered as completely as possible by residual heat from the CHP-unit operated with the produced biogas. To do this, the heat demand is first calculated as follows.

- The ambient temperatures used as a calculation basis are the average monthly temperatures at the Marmul site in Oman (WorldWeatherOnline 2020). These temperature profiles are comparable to temperatures measured at different other oil fields within the gulf region.

- The calculation of the thermal energy needed for fermenter heating is subsequently carried out. For this, it is assumed that each fermenter consist of a floor plate made of concrete (thickness $0.2 \mathrm{~m}$ ) covered with polyethylene foil (thickness $0.2 \mathrm{~mm}$ ) and polystyrol rigid foam (thickness $5 \mathrm{~cm}$ ). The wall consists of concrete (thickness 0.2 $\mathrm{m}$ ) covered with polystyrol rigid foam (thickness $0.1 \mathrm{~m}$ ) and the cover is made of EPDM roofing foil (thickness $2 \mathrm{~mm}$ ) and polyethylene foil (thickness $0.2 \mathrm{~mm}$ ). This allows to calculate the heat transfer coefficient $U$ for the individual building components (i.e. floor plate, wall and cover) using Equation 2.

$U=\frac{1}{\frac{1}{\alpha_{i}}+\frac{d_{1}}{\lambda_{1}}+\frac{d_{n}}{\lambda_{n}}+\frac{1}{\alpha_{a}}}$

- $\lambda$ is the thermal conductivity of the respective material, $d$ is the component layer thickness and $\alpha$ is the heat transfer coefficient of the surrounding atmosphere.
- The overall heat flow through the fermenter $\dot{Q}_{T, F e r m}$ was subsequently calculated using Equation 3.

$$
\dot{Q}_{T, F e r m}=\Sigma(U A \Delta T)
$$

- $A$ is the component surface and $\Delta T$ is the temperature difference.

- The needed values for Eqs. 2 and 3 were taken from the literature (Stephan et al. 2019). Moreover, care was taken to ensure that the fermenter size did not exceed $3500 \mathrm{~m}^{3}$, as larger fermenters are likely to have difficulties with mixing and heating (Scholwin et al. 2007). For cases 3 and 4 , this means that 2 fermenters are required for the implementation of anaerobic digestion.

- The calculations of the thermal energy need for vapothermal pre-treatment are based on heating both dry biomass fraction and water content within the biomass to the desired pre-treatment temperature of $150{ }^{\circ} \mathrm{C}$, heating and evaporation of water needed in the process and superheating the steam to $150{ }^{\circ} \mathrm{C}$. Heating was calculated by multiplying the specific heat capacity of reed $\left(1,200 \mathrm{~J} \mathrm{~kg}^{-1} \mathrm{~K}^{-1}\right)$ (FNR 2021), water (4,366 J $\left.\mathrm{kg}^{-1} \mathrm{~K}^{-1}\right)$ and steam $\left(2,572 \mathrm{~J} \mathrm{~kg}^{-1} \mathrm{~K}^{-1}\right)$ with the respective quantities and the respective temperature delta. Evaporation was calculated by multiplying the amount of needed vapothermal pre-treatments (batches) with the required energy for evaporation $(2,257 \mathrm{~kJ})$ and the required amount of water (whereby the required amount of water was calculated using the ideal gas equation). The specific energy requirements calculated on this basis serve only as an approximation, since heat losses and heat recovery are not taken into account. Depending on the process engineering implementation, deviations may occur.

Since the heat demand of the overall biogas provision system varies greatly over the course of the year due to the different ambient temperatures, it is quantified separately in addition to the mass and energy balances presented below. The emerging heat during electricity generation within the engine-driven CHP-unit assumed here is available at two different temperature levels. It is assumed that $40 \%$ of the produced heat is waste gas heat with a temperature of around 300 to $500{ }^{\circ} \mathrm{C}$ and $60 \%$ of the produced heat originates from cooling water and motor oil at a temperature level of around 90 to $120^{\circ} \mathrm{C}$ (Kaltschmitt et al. 2016). The high temperature heat is used to realize vapothermal pre-treatment at $150{ }^{\circ} \mathrm{C}$ while the low temperature heat is used for heating the digestate within the fermenter. The remaining heat (i.e. the surplus heat not needed within these two system elements) is considered as a loss. In all cases, continuous heat and electricity production is assumed during $8,500 \mathrm{~h} \mathrm{a}^{-1}$ (operating hours 
per year). Inter alia, the steps described in chapter 2.1 and 2.2 are illustrated under the heading "Technical Analysis" in Fig. 2.

Before the produced biogas is converted into electricity and heat within a CHP-unit, it is stored in an aerial roof on top of the fermenter. The size of this gas storage is designed to cover the biogas produced within one day (i.e. $24 \mathrm{~h}$ ). After storage, a gas purification takes place. This includes coarse desulfurization by air injection and gas drying by condensation (Kaltschmitt et al. 2016).

The digestate remaining after fermentation can be used as a fertilizer for the surrounding reed beds. However, in order to both save transportation costs and water, there is a fermentation residue separation step using a screw press. The digestate is thereby separated into two fractions: a solid fraction with a dry matter content of $50 \mathrm{wt} \%$ and a liquid fraction. The liquid fraction is used for mashing fresh substrate. This also has the advantage that microorganisms (i.e. active biomass) are returned to the system helping to make the process more stable.

\section{Mass and energy balances}

For the biogas systems designed according to the aforementioned procedure, corresponding mass and energy balances are drawn up. The mass balances are determined using the substrate data (Table 2) and assumptions presented in chapter 2.1. For the preparation of the energy balances, the characteristics shown in Table 3 are used. The amount of electricity required during operation is thereby assigned to each of the designed plant components. In addition, the efficiency losses during conversion of biogas into electricity and heat are taken into account.

$1 \mathrm{~kg}$ dry matter of the respective substrate mix is defined as the reference value within the mass and energy balances. According to Table 3, a maximum amount of methane that can be formed via anaerobic digestion from this substrate mix is then assigned to this value. Building on this, it is shown exactly what percentage of the energy stored in this form is required for the respective process steps. Furthermore, the amount of additionally needed water is shown.

\section{Economic Assessment}

An economic evaluation was carried out on the basis of the annuity cost assessment in accordance with VDI guideline 6025 (VDI 2012). In this methodological approach, various cost categories, namely capital-based costs, consumptionbased costs and operational costs are first defined and subsequently determined. Then, the so-called annuity of the respective costs is calculated. Therefore, an annuity factor (a) depending on both the assumed economic lifetime of the considered system $(T)$ and the interest rate $(q)$ is calculated Equation 4. The interest rate is assumed to be $4 \% \mathrm{a}^{-1}$ and the considered economic lifetime is 20 a for the overall treatment plant. Some system components must already be replaced during this time due to their shorter lifespan (Table 4).

$a=\frac{q-1}{1-q^{-T}}$

The annuity of capital-based costs $\left(A N_{K}\right)$ is calculated based on the previously determined investment costs $\left(A_{0}\right)$ according to Equation 5. The calculation also takes into account a component-specific residual value factor $(R)$, a factor for inclusion of repairs $\left(f_{K}\right)$ and a price-dynamic annuity factor for repair payments $\left(b a_{I N}\right)$. These factors were calculated based on the guideline VDI 6025, assuming a price change of $2 \% \mathrm{a}^{-1}$ for capital-linked payments and $3 \% \mathrm{a}^{-1}$ for consumption-linked payments.

Table 4 Key parameters of the economic assessment

\begin{tabular}{|c|c|c|c|}
\hline Parameter & Value & Parameter & Value \\
\hline General frame conditions & & Technical lifetime & \\
\hline Observation period & $20 \mathrm{a}$ & Substrate storage & $20 \mathrm{a}$ \\
\hline Availability & $8500 \mathrm{~h} \mathrm{a}^{-1}$ & Vapothermal reactor & $20 \mathrm{a}$ \\
\hline $\begin{array}{l}\text { Requested rate of } \\
\text { interest }\end{array}$ & $4 \%$ & Wet milling system & $10 \mathrm{a}$ \\
\hline Base year & 2019 & Fermenter & $20 \mathrm{a}$ \\
\hline Costs & & Gas storage & $20 \mathrm{a}$ \\
\hline Diesel & $0.5 € \mathrm{~kg}^{-1}$ & Screw press & $10 \mathrm{a}$ \\
\hline Lubricating oil & $2.5 € \mathrm{~kg}^{-1}$ & Gas purification system & $20 \mathrm{a}$ \\
\hline Enzyme mixture & $300 € \mathrm{~kg}^{-1}$ & CHP-unit & $10 \mathrm{a}$ \\
\hline Staff & $15 € \mathrm{~h}^{-1}$ & & \\
\hline
\end{tabular}

Table 3 Key data for the preparation of energy balances

\begin{tabular}{lll}
\hline Plant component & Power consumption & Source \\
\hline Comminution + Substrate input & $1.2 \mathrm{kWh} \mathrm{m}^{-3}$ & Vogelsang GmbH \& Co. KG (2020) \\
Fermenter mixing & $20 \mathrm{~W} \mathrm{~m}^{-3}$ & Dachs and Rehm (2006) \\
Gas purification & $0.12 \mathrm{kWh} \mathrm{d}^{-1} / \mathrm{m}^{3} \mathrm{~h}^{-1}$ & Häring et al. (2010) \\
Phase separation & $1.6 \mathrm{kWh} \mathrm{m}^{-3}$ & Bacenetti et al. (2013) \\
\hline
\end{tabular}


$A N_{K}=A_{0}(1-R) a+f_{K} A_{0} b a_{I N}$

Subsequently, the annuity of capital-based costs $\left(A N_{K}\right)$ was summed up with the annuity of consumption-based costs $\left(C_{C}\right)$ and operational costs $\left(C_{O}\right)$ in order to calculate the overall costs. The overall procedure is illustrated in Fig. 2.

Purchase costs of the individual system compounds were estimated from literature (Delzeit and Kellner 2013; MLUK 2006), from open access reports (FNR 2020; Fuebbeker 2018; Laub et al. 2015; Polster and Brummack 2004) and from statements made by plant manufacturers (Rueckert 2020; Vogelsang GmbH \& Co. KG 2020). Since vapothermal pre-treatment is not state of the art yet, costs for the reactor were estimated by material requirements (see (Towler and Sinnot 2013)). As, in the latter, the underlying data refer to the year 2010, a conversion to the year 2019 was performed using the chemical engineering plant cost index (CEPCI) according to (Equation 6). If a conversion from US\$ to $€$ was necessary, the average exchange rate of the respective year has been used.

CostinyearA $=$ Costinyear $B \frac{\text { CEPCIyear } A}{\text { CEPCIyear } B}$

Furthermore, various additional costs are taken into account occurring during the installation of such a system. Expenses for planning, approval and installation as well as expenditures for the development of land are assumed to be $10 \%$ of the total costs for equipment $\left(\sum \mathrm{A} 0_{\mathrm{E}}\right)$. Additionally, overhead costs of $10 € \mathrm{~kW}_{\mathrm{el}}{ }^{-1}$ installed power and costs for working capital of $15 \%$ of the total investment costs $\left(\sum \mathrm{A} 0_{\text {Total }}\right)$ are assumed.

The consumption-based costs are composed of auxiliaries such as lubricating oil for the CHP-unit (consumption $0.2 \mathrm{~g}$ $\mathrm{kWh}^{-1}$ (MWM 2021)), Diesel fuel for substrate transportation on site (consumption $25 \mathrm{~L} \mathrm{~h}^{-1}$ ) and additives for fermentation such as enzyme mixtures and nutrients (consumption $1.9 \mathrm{~kg} \mathrm{t}_{\mathrm{vS}}^{-1}$ (FNR 2011)). It is assumed that reed and sewage sludge used as substrates are free of charge available at the plant gate.

Operational costs are calculated as the sum of the costs for staff, insurance and maintenance. Staff costs are assumed to be $15 € \mathrm{~h}^{-1}$ and $8.5 \mathrm{~h}$ of a worker are required per $\mathrm{kW}_{\mathrm{el}}$ installed power. Filling and unloading of the vapothermal reactor takes $0.5 \mathrm{~h}$ each. Insurance costs are assumed to be $0.5 \%$ and maintenance costs $2 \%$ of $\sum \mathrm{A} 0_{\mathrm{E}}$.

The overarching goal of the calculations is to determine the electricity production costs for biogas plants operated with and without vapothermal pre-treatment. Simultaneously, this allows evaluating whether anaerobic digestion could be competitive with the conventional production of electricity via Diesel generators on sites as described in chapter 1. Calculation of the electricity production costs ( $L C O E$ ) was done according to Equation 7, taking into account the own power demand of the system.

$$
L C O E=\frac{\left(A N_{K}+C_{C}+C_{O}\right)}{\text { Power }_{\text {produced }}-\text { Power }_{\text {consumed }}}
$$

The key parameters of the economic assessment are summarized in Table 4. Due to uncertainties originating from the assumptions made as well as the variety of the assumed prices, additionally a sensitivity analysis is performed. Therefore, the investment costs, the economic lifetime of the plant, the rate of interest and the availability are varied in a range of $\pm 50 \%$, respectively.

Diesel equivalent prices are calculated by multiplying the price per kWh stored energy in the generated biogas with the heating value of diesel $\left(10.4 \mathrm{kWh} \mathrm{L}^{-1}\right)$. It is thereby assumed that the conversion of Diesel fuel takes place in a CHP-unit at the same efficiency levels as the conversion of biogas to electricity and heat. Finally, using the $\mathrm{CO}_{2}$ emissions during combustion of Diesel fuel $\left(2.65 \mathrm{~kg} \mathrm{~L}^{-1}\right), \mathrm{a} \mathrm{CO}_{2}$ price to reach the diesel equivalent costs is determined.

Lastly, by means of a literature research, a comparison with other thermal pre-treatment methods aiming to improve the anaerobic digestibility of different substrates is drawn. In the context of this comparison, the results of this study are compared with the results of investigations on steam explosion and hydrothermal pre-treatment.

\section{Results and Discussion}

The following chapter is divided into 3 parts.

- At first, the results of the design of the biogas systems concerning the size of fermenters, the amount of substrate to be used and the demand for water, electricity and heat are presented. In addition, it is checked whether the required heat can be provided via the waste heat of the CHP-unit.

- Based on this, in the second part the mass and energy balances are presented for biogas systems with and without the implementation of a vapothermal pre-treatment using a selected example case.

- Within the subsequent economic assessment, the results of the annuity cost accounting are presented and discussed. The same is true for the results of the parameter variations defined in chapter 2.3 .

\section{Design of the biogas system}

Some of the most important parameters concerning the plant configurations considered here are shown in Table 5. Due to 
Table 5 Specifications for the considered scenarios

\begin{tabular}{|c|c|c|c|c|c|c|c|c|}
\hline & \multicolumn{2}{|l|}{ Case I } & \multicolumn{2}{|c|}{ Case II } & \multicolumn{2}{|l|}{ Case III } & \multicolumn{2}{|l|}{ Case IV } \\
\hline & $\mathrm{a}$ & $\mathrm{b}$ & a & $\mathrm{b}$ & $\mathrm{a}$ & $\mathrm{b}$ & A & $\mathrm{b}$ \\
\hline \multicolumn{9}{|l|}{ Input in $\mathrm{kg}_{\mathrm{VS}} \mathrm{d}^{-1}$} \\
\hline Reeds & 2,681 & 2,302 & 5,247 & 4,505 & 11,595 & 9,955 & 15,020 & 12,897 \\
\hline Sewage sludge & 894 & 767 & 1,749 & 1,502 & 3,865 & 3,318 & 5,007 & 4,299 \\
\hline Fermenter volume in $\mathrm{m}^{3}$ & 1,182 & 982 & 2,314 & 1,923 & 5,113 & 4,249 & 6,624 & 5,504 \\
\hline \multicolumn{9}{|l|}{ Electricity consumption in $\mathrm{kWh} \mathrm{d}^{-1}$} \\
\hline Comminution + Substrate input & 57 & 47 & 111 & 92 & 245 & 204 & 318 & 264 \\
\hline Fermenter mixing & 189 & 157 & 370 & 308 & 818 & 680 & 1060 & 881 \\
\hline Gas purification & 4 & 4 & 9 & 9 & 19 & 19 & 25 & 25 \\
\hline Phase separation & 76 & 63 & 148 & 123 & 327 & 272 & 424 & 352 \\
\hline \multicolumn{9}{|l|}{ Heat consumption in $\mathrm{kWh} \mathrm{d}^{-1}$} \\
\hline$\varnothing$ Fermentation & 716 & 597 & 1,299 & 1,121 & 2,679 & 2,302 & 3,208 & 2,741 \\
\hline Vapothermal pre-treatment & - & 177 & - & 347 & - & 676 & - & 875 \\
\hline Water consumption in $\mathrm{m}^{3} \mathrm{~d}^{-1}$ & 4.3 & 3.6 & 8.4 & 6.9 & 18.6 & 15.5 & 24.1 & 20.0 \\
\hline
\end{tabular}

the higher biogas yield after vapothermal pre-treatment, both the required quantity of substrate and the fermenter volume decrease compared to the case without a pre-treatment. The vapothermal pre-treatment also has a positive influence on the demand for electricity and on water consumption for mashing the substrate. However, naturally the heat demand increases in this case.

Within a CHP-unit heat at different temperature ranges is provided (chapter 2). In order to allow for a vapothermal pre-treatment all year round, always sufficiently high temperature heat is needed. Therefore, the amount of heat provided by the CHP-unit is compared to the quantity of heat required; this is realized in Fig. 3 exemplarily for Case IV. A similar picture results in each other case.

Fig. 3 indicates that the thermal energy provided clearly exceeds the consumption in the case shown for biogas production without vapothermal pre-treatment. Thereby, in the coldest months, 1.7 times as much energy as required is provided while in the hottest months the heat production exceeds the demand by a factor of 199. In Case I a, II a and III a (for definition see Table 5), the ratios of heat provision to heat consumption in the coldest months are 1.4, 1.4 and 1.5 , respectively. The ratios for the hottest months are 59, 66 and 146, respectively.

From Fig. 3 it also becomes obvious that in the shown case implementing vapothermal pre-treatment, high temperature thermal energy is sufficiently available to perform the pre-treatment in all months. In parallel, enough low temperature heat is provided from the CHP-unit to heat up the digestate. This is also true for other considered cases, with the exception of Case II. There, in the coldest months of the year, the ratio between provided low temperature energy to required high temperature energy equals 0.98 . However,

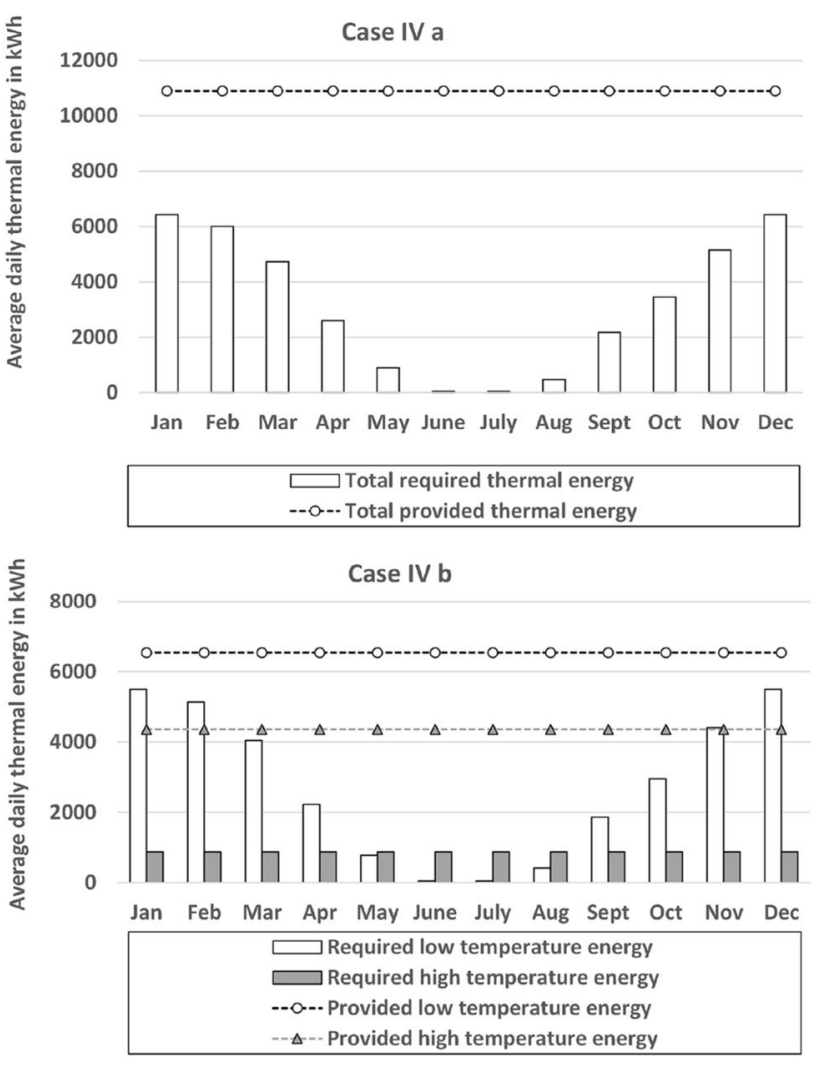

Fig. 3 Required and provided thermal energy in Case IV (for definition of the cases see Table 5)

this could easily be compensated by the remaining surplus of high temperature thermal energy. A feasibility of the selected system in the mesophilic temperature range (i.e. at $37^{\circ} \mathrm{C}$ ) is accordingly possible in all cases considered. 


\section{Mass and energy balances}

Fig. 3 makes it also evident that particularly in the hot summer months still substantial quantities of thermal energy remain. To avoid an overheating of the CHP-units, this thermal energy has to be discharged to the surrounding atmosphere. Technically, this can be realized by the use of cooling water. However, it could also be advantageous to use this thermal energy even further. One possibility therefore is the integration of absorption chillers. Here, an absorption fluid is evaporated by removing heat from the chilled water. Thus, cooling can be provided, e.g. for (operating-) buildings and/ or for removing moisture from the biogas stream. Such a configuration is not subject of the investigations realized here, but might be an option to further optimize such systems (e.g. (Bruno et al. 2009)).

To show more precisely what amounts of energy can be made available as electricity and heat (and how much heat then still has to be dissipated), mass and energy balances are given in Fig. 4 exemplarily for Case IV (for definition see Table 5) as average values of one year. Similar results are also obtained in the other cases considered. For an easier comparison, the results are related to $1 \mathrm{~kg}$ of dry matter (substrate mix of reed and sewage sludge).

The assumptions made in Chapter 2 result in a reduction of dry matter of 30 and $34 \%$ by anaerobic digestion in Case IV $a$ and $b$ (for definition see Table 5), respectively. Both the highest thermal and electrical energy consumption are attributed to anaerobic digestion. Electrical energy is thereby needed for fermenter mixing while thermal energy is necessary to ensure mesophilic conditions and compensate the occurring heat losses. Fig. 4 also shows that vapothermal pre-treatment reduces energy consumption both in absolute terms (due to the smaller fermenter volume) and in relative terms (due to the higher proportion of degradable dry matter). Thus, after deduction of the energy required for all necessary parts of the biogas plant and after taking into consideration the efficiency losses during conversion of the biogas within the CHP-unit, 66.9 and $68.6 \%$ of the energy stored in the generated biogas can be made usable in Case IV a and $b$, respectively (for the definition of the cases see Table 5). In Case IV b, however, parts of the thermal energy are again required for the vapothermal pre-treatment. Thus, the implementation of vapothermal pre-treatment leads to higher
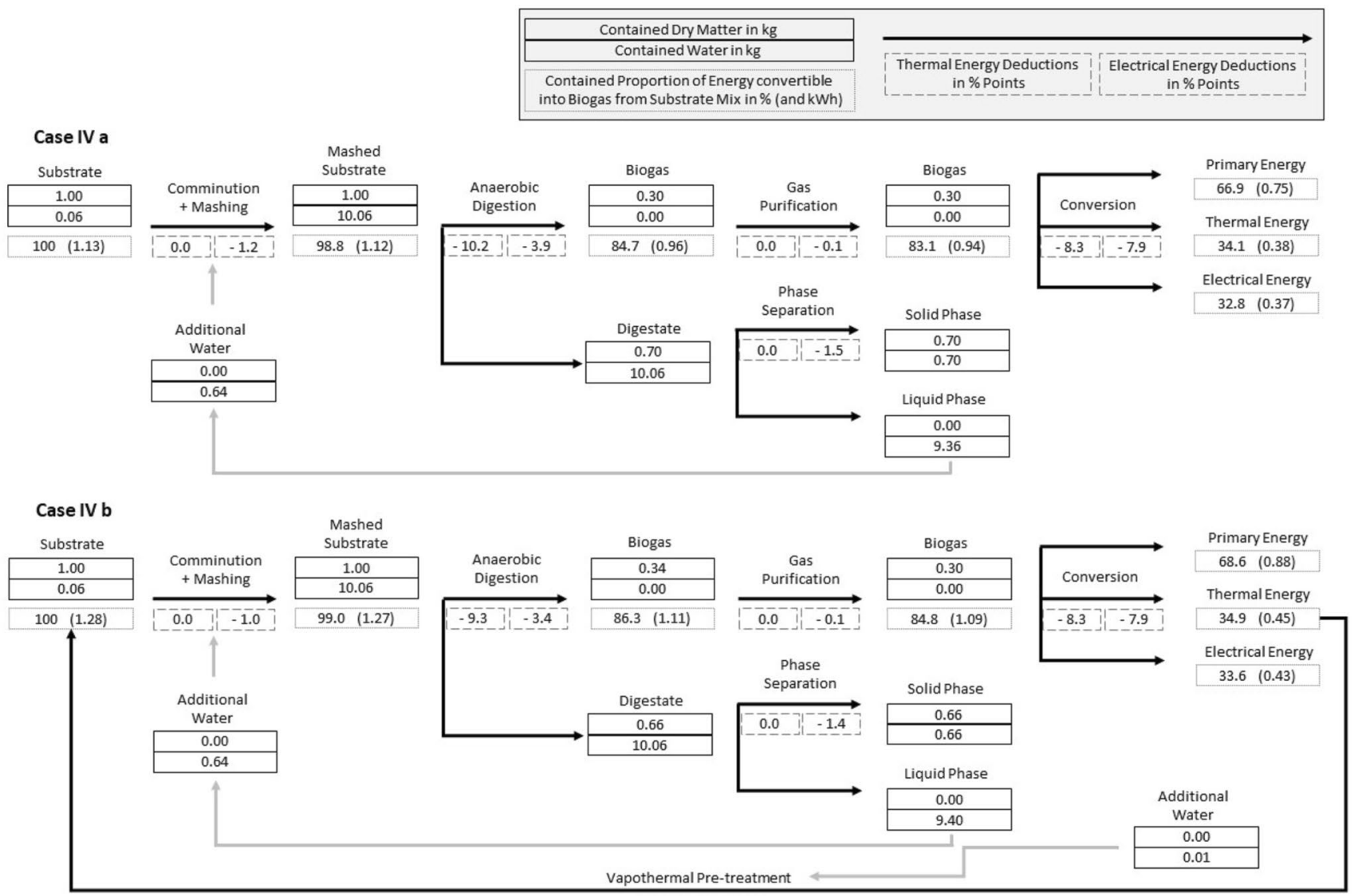

$\left[-0.0-\left.1\right|^{-2}-4.6\right.$

Fig. 4 Mass and energy balance based on $1 \mathrm{~kg}$ dry matter for Case IV a and b (for definition of the cases see Table 5) 
amounts of usable electrical energy but lower amounts of usable thermal energy. If there is no further possibility of using the generated heat, less residual heat would have to be dissipated in this case.

\section{Economic Assessment}

\section{Costs of electricity}

The technical design of all plants allows for a continuous operation with the installed capacity to cover base load (Table 6) (Lauer et al. 2020). Therefore, the quantity of the provided electrical energy is equal in each case $a$ and $b$. The differences within the electricity consumption between case $a$ and $b$ are mainly due to a varying energy consumption during stirring (caused by different fermenter sizes) and during feeding and dewatering.

The results show that the specific electricity provision costs can be reduced by a vapothermal pre-treatment under the assumptions made here. However, this only applies if the plant exceeds a certain size. In the cases considered here, this is true for all plants with an installed electric power above $75 \mathrm{~kW}$, while in Case I (installed electric power 75 $\mathrm{kW}$ ) the specific electricity production costs are lower without the implementation of a vapothermal pre-treatment.

Furthermore, an increase of the plant capacity reduces the costs more significantly than the implementation of a vapothermal pre-treatment. The highest electricity production costs are incurred in Case I b with $0.186 € \mathrm{kWh}^{-1}$, while the lowest costs of $0.120 € \mathrm{kWh}^{-1}$ are given in Case IV b. Such a cost reduction with an increase in plant size is in line with the findings from other studies. An increase of plant size initially causes large cost reductions followed by low cost reduction at comparatively larger plant sizes (Walla and Schneeberger 2008).
The electricity provision costs (LCOE) calculated here are within a similar range as other studies investigating biogas production from similar feedstock in plants with comparable sizes. For instance in Southern Italy, the electricity production costs applying co-digestion of giant reed (Arundo donax L.) silage and livestock waste are calculated to be between 0.13 and $0.17 € \mathrm{kWh}^{-1}$ (Sgroi et al. 2015). In the case of using rice straw (Oryza sativa) as a biogas substrate in South-East Asian countries, even lower electricity provision costs (LCOE) of around $0.07 € \mathrm{kWh}^{-1}$ were estimated (Baetge and Kaltschmitt 2018).

In plants of a similar size range between 75 and $500 \mathrm{~kW}$ installed electric power operated with substrates originating from specially cultivated energy crops, the electricity production costs (LCOE) are between 0.17 and $0.29 € \mathrm{kWh}^{-1}$ and thus unequally higher. Substrate costs thereby account for between 16 and $42 \%$ of the electricity generation costs (FNR 2016). Compared to this, within this assessment it is assumed that the substrates are free-of-charge by-products. This constitutes a major economic advantage, although the specific methane yield of reed is significantly lower compared to energy crops resulting in a need for larger fermenters and thus higher investment costs.

\section{Comparison with electricity generation from Diesel fuel}

In the geographic areas covered by this study, Diesel fuel is almost always available at very low cost because it is subsidised by the respective governments. Therefore, biogas plants are not competitive in most cases when only the electricity provision costs are considered. For example, the electricity production costs (LCOE) of a Diesel generator located at remote locations in Iran with a capacity of $800 \mathrm{~kW}$ are $0.09 € \mathrm{kWh}^{-1}$ (Baneshi and Hadianfard 2016). Electricity provision costs (LCOE) in the same order of magnitude are reported for remote locations in Saudi Arabia for Diesel

Table 6 Results of the economic assessment (for definition of the cases see Table 5)

\begin{tabular}{|c|c|c|c|c|c|c|c|c|}
\hline & \multicolumn{2}{|l|}{ Case I } & \multicolumn{2}{|l|}{ Case II } & \multicolumn{2}{|l|}{ Case III } & \multicolumn{2}{|l|}{ Case IV } \\
\hline & A & $\mathrm{b}$ & A & $\mathrm{b}$ & $\mathrm{a}$ & $\mathrm{b}$ & $\mathrm{a}$ & $\mathrm{b}$ \\
\hline \multicolumn{9}{|l|}{ Annuity in $€ \mathrm{a}^{-1}$} \\
\hline Capital-based payment & 51,357 & 50,896 & 97,212 & 93,245 & 179,676 & 168,921 & 207,749 & 192,314 \\
\hline Consumption-based payment & 6,919 & 8,912 & 9,230 & 10,948 & 14,904 & 15,940 & 17,890 & 18,558 \\
\hline Operational payment & 36,540 & 40,542 & 72,178 & 78,329 & 147,200 & 149,900 & 178,824 & 181,497 \\
\hline Total & 94,816 & 100,350 & 178,621 & 182,522 & 341,780 & 334,761 & 404,463 & 392,369 \\
\hline Produced electricity in $\mathrm{kWh}$ & 637,500 & 637,500 & $1,360,000$ & $1,360,000$ & $3,060,000$ & $3,060,000$ & $3,825,000$ & $3,825,000$ \\
\hline Consumed electricity in $\mathrm{kWh}$ & 119,009 & 99,158 & 232,920 & 194,068 & 514,688 & 428,836 & 666,747 & 555,531 \\
\hline Electricity production costs (LCOE) in $€ \mathrm{kWh}^{-1}$ & 0.183 & 0.186 & 0.158 & 0.157 & 0.134 & 0.127 & 0.128 & 0.120 \\
\hline Diesel fuel equivalent costs in $€ \mathrm{~L}^{-1}$ & 1.47 & 1.51 & 1.21 & 1.19 & 1.08 & 1.01 & 1.09 & 1.00 \\
\hline $\begin{array}{l}\mathrm{CO}_{2} \text { price to reach the Diesel fuel equivalent costs } \\
\text { in } € \mathrm{t}^{-1}\end{array}$ & 366.2 & 380.0 & 266.9 & 259.3 & 218.8 & 191.1 & 221.4 & 189.7 \\
\hline
\end{tabular}


generators with a capacity of $342 \mathrm{~kW}$ (Al-Shamma'a et al. 2020).

For the case considered here, however, in interaction with wetlands for water purification, there are also further advantages such as savings on disposal costs for the reed grass. Thus, it is interesting to understand at what Diesel fuel price a biogas plant would be economically competitive under the chosen assumptions since Diesel fuel prices could increase in the years to come due to dwindling oil reserves, a changing local / regional policy on subsidies and / or a pricing of $\mathrm{CO}_{2}$ emissions.

Therefore, Diesel fuel equivalent costs were calculated and are displayed in Table 6. Furthermore, the Diesel fuel equivalent costs were assigned to necessary $\mathrm{CO}_{2}$ prices required to achieve this value at the assumed current price. Highest Diesel fuel equivalent costs of $1.51 € \mathrm{~L}^{-1}$ were found in Case I b (for definition see Table 5). By the implementation of vapothermal pre-treatment and the investigated increased plant size, the Diesel fuel equivalent costs could be decreased to $1.00 € \mathrm{~L}^{-1}$ in Case IV b. This would reduce the necessary penalties on $\mathrm{CO}_{2}$ emissions from Diesel fuel combustion from $380.0 € \mathrm{t}^{-1}$ to $189.7 € \mathrm{t}^{-1}$. Currently, it is not expected that such a high $\mathrm{CO}_{2}$ price will be introduced. However, to limit global warming to $2{ }^{\circ} \mathrm{C}$, the $\mathrm{CO}_{2}$ price would have to rise globally to $44-88 € \mathrm{t}^{-1}$ by 2030 (World Bank Group 2017). To achieve the more ambitious increase limit of $1.5^{\circ} \mathrm{C}$, the $\mathrm{CO}_{2}$ price would have to be $130-350$ $€ \mathrm{t}^{-1}$ and thus in the range of the penalties required here (Edenhofer et al. 2018).

\section{Sensitivity analysis}

With the approach used here, results show typically uncertainties of approximately $\pm 30 \%$ (Peters et al. 2003). Therefore, a sensitivity analysis is performed as described in chapter 2.2. To estimate their effect on the electricity provision costs (LCOE), investment costs, plant lifetime, rate of interest and plant availability (yearly full load hours) are varied in a range of $\pm 50 \%$ based on the initial case. The results of this parameter variation are exemplarily shown for Case I $b$ and IV $b$ (for definition see Table 5) in Fig. 5, since these cases are characterized by the highest and the lowest specific electricity provision costs of all cases considered here. It turns out that in this range and with the selected starting point, varying the interest rate has the smallest effect on the electricity production costs, followed by plant lifetime and investment costs. The variation of these parameters has a linear course. For the plant availability (yearly full load hours) showing a very large effect on the electricity production costs (LCOE), this is not the case. Here, the variation has an exponential course. For instance, in Case $\mathrm{I}$ b, a $10 \%$ decrease of the plant availability (i.e. $8,500 \mathrm{~h}$ to $7,650 \mathrm{~h}$ ) results in an increase of the electricity production
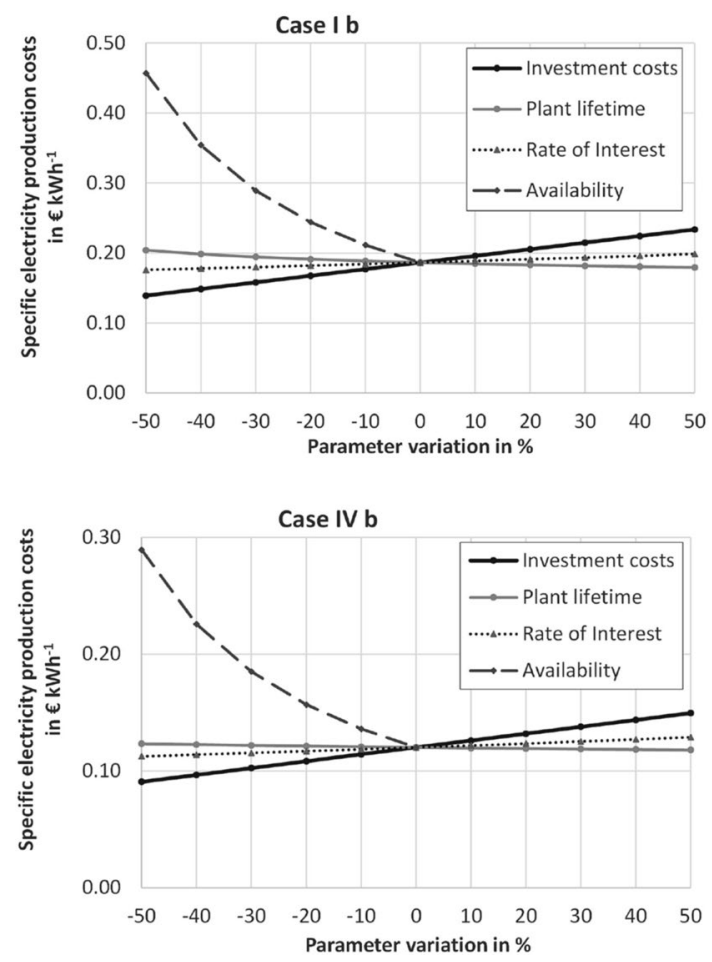

Fig. 5 Sensitivity of the electricity production via biogas from anaerobic digestion in Case I $\mathrm{b}$ and Case IV $\mathrm{b}$ in respect of investment costs, plant lifetime, rate of interest and availability (for definition of the cases see Table 5)

costs (LCOE) of $0.03 € \mathrm{kWh}^{-1}$. Compared to this, the other parameters assessed here are only marginally influence the electricity production costs (LCOE) in the chosen range of variation. Therefore, it is very important to ensure the highest possible plant availability (high yearly full load hours).

\section{Comparison with other pre-treatment options}

Currently, there are numerous different techniques to pretreat substrates to make them more readily degradable under anaerobic conditions. With regard to the functioning mechanisms of the respective pre-treatments, reference is made to existing reviews (e.g. (Scherzinger and Kaltschmitt 2021)). However, there is actually only a very limited number of studies available dealing with the economic efficiency of these pre-treatment technologies on an industrial scale, although such investigations are essential for a broad application.

In order to compare the vapothermal pre-treatment with other pre-treatment processes, some studies dealing with the economic viability of pre-treatment methods to enhance anaerobic digestibility are compared with the results of this study. Due to the limited data availability, studies dealing with different quantities of biomass to be pre-treated as well 
Table 7 Comparison of the obtained results with data from other studies investigating different pre-treatment options

\begin{tabular}{|c|c|c|c|c|c|c|}
\hline $\begin{array}{l}\text { Type of pre-treat- } \\
\text { ment }\end{array}$ & $\begin{array}{l}\text { Considered sub- } \\
\text { strate }\end{array}$ & $\begin{array}{l}\text { Method of biogas } \\
\text { production }\end{array}$ & Size & Production costs & $\begin{array}{l}\text { Savings compared } \\
\text { to production } \\
\text { without pre-treat- } \\
\text { ment }\end{array}$ & Source \\
\hline Vapothermal & Reeds & $\begin{array}{l}\text { Wet fermentation } \\
\text { with sewage } \\
\text { sludge as co- } \\
\text { substrate }\end{array}$ & $160-450 \mathrm{~kW}_{\mathrm{el}}$ & $\begin{array}{l}0.12-0.19 € \\
\mathrm{kWh}^{-1}\end{array}$ & up to $6.7 \%$ & Current work \\
\hline Steam explosion & Wheat straw & $\begin{array}{l}\text { Solid state fermen- } \\
\text { tation }\end{array}$ & $\begin{array}{c}200,000 \mathrm{t} \mathrm{a}^{-1} \text { (raw } \\
\text { material based } \\
\text { on dry mass) }\end{array}$ & $0.18 € \mathrm{~m}^{-3}$ Biogas & $35.7 \%$ & (Shafiei et al. 2013) \\
\hline Hydrothermal & Microalgae & Wet fermentation & $\begin{array}{l}9,125 \mathrm{t} \mathrm{a}^{-1} \text { (raw } \\
\text { material based } \\
\text { on dry mass) }\end{array}$ & $\begin{array}{c}0.15-0.20 € \\
\mathrm{~m}^{-3}{ }_{\text {Biogas }}\end{array}$ & $36.4-76.5 \%$ & (Xiao et al. 2020) \\
\hline Thermal-acid & Cow manure & Wet fermentation & $\begin{array}{l}\text { Approx. } 240,000 \mathrm{t} \\
\mathrm{a}^{-1} \text { (raw material } \\
\text { based on fresh } \\
\text { mass) }\end{array}$ & No specification & Not profitable & (Passos et al. 2017) \\
\hline Thermal-alkali & Cow manure & Wet fermentation & $\begin{array}{l}\text { Approx. } 240,000 \mathrm{t} \\
\mathrm{a}^{-1} \text { (raw material } \\
\text { based on fresh } \\
\text { mass) }\end{array}$ & No specification & Not profitable & (Passos et al. 2017) \\
\hline
\end{tabular}

as different types of biomass had to be included. The corresponding results are displayed in Table 7.

For steam explosion pre-treatment of wheat straw at 180 ${ }^{\circ} \mathrm{C}$, a reduction of the biogas production costs of roughly 36 $\%$ can be realized (Shafiei et al. 2013). However, the study considers a treatment of much higher quantities of substrate (200,000 $\mathrm{t} \mathrm{a}^{-1}$ based on dry matter) compared to the present study $\left(<10,000 \mathrm{t} \mathrm{a}^{-1}\right.$ based on dry matter for Case IV (for definition see Table 5)). Following the 0.6-rule stating that doubling the size of a plant results in $60 \%$ increase in equipment costs (Tribe and Alpine 1986) steam explosion for plants with similar sizes as considered here could have also a lower cost advantage. Steam explosion is a treatment option most similar to the vapothermal pre-treatment considered here. It also takes place in a steam atmosphere, but uses higher temperatures ( 180 to $240{ }^{\circ} \mathrm{C}$ ) and higher pressure ( 1 to $3.5 \mathrm{MPa}$ ). At the end of this process, the pressure is suddenly released causing the treated substrate to tear. Due to the higher requirements on the reactors in terms of temperature and pressure resistance as well as the need for a pressure-relief vessel, this technology is more technologically demanding than vapothermal pre-treatment.

Another possible option for substrate pre-treatment is hydrothermal pre-treatment. Here, the substrate is surrounded by liquid water, mostly at elevated temperatures above $100{ }^{\circ} \mathrm{C}$ and a pressure above ambient pressure. This option is especially suitable for biomass available with a high water content. For microalgae pre-treated in this way at $160{ }^{\circ} \mathrm{C}$, it was shown that the biogas production costs via subsequent anaerobic digestion can be reduced by 36 up to $77 \%$, depending on whether the heat for pre-treatment is provided by conventional burners or solar heating (Xiao et al. 2020). Although algae cultivation is typically relatively expensive, the biogas production subsequent to hydrothermal pre-treatment lies in the range of biogas produced from wheat straw after steam explosion.

Hydrothermal pre-treatment can also be extended by the addition of chemicals such as acids or alkalis. For the example of cow manure as a substrate, the specific methane formation potential during subsequent anaerobic digestion can be increased by more than $20 \%$ due to such a pre-treatment (Passos et al. 2017). However, an economic analysis showed that fermentation is carried out more cost efficient without such a pre-treatment because the high costs for these chemicals make this type of pre-treatment not economically viable. However, other advantages, such as a better suitability of the fermentation residues as fertilizer, could change this picture.

Overall, the vapothermal pre-treatment can also prevail from an economic point of view and could be competitive compared to other pre-treatment options. However, it can only exploit its cost advantages with larger installed capacities. Nevertheless, it must always be borne in mind that each type of substrate and each location requires an adapted mode of operation to achieve the best results.

\section{Conclusion}

Eight different biogas plant configurations with installed electric power from 75 to $450 \mathrm{~kW}$, each with and without vapothermal pre-treatment, were investigated. In all cases, a 
co-fermentation of reeds with sewage sludge was assumed. By applying such a process, energy could be provided in an environmentally friendly way by using residual materials. The electricity provision costs (LCOE) were calculated using the annuity method, considering newly built plants at remote locations nearby a constructed wetland in the Persian Gulf states.

The electricity generation costs in the considered biogasbased system decrease clearly with increasing plant size; i.e. for the capacity range assessed here it is valid that the larger the biogas system the lower the electricity provision costs. The availability of the whole installation was found to be the most important parameter affecting the electricity generation costs; i.e. the better the biogas system is maintained to achieve the desired operation hours the lower the electricity provision costs.

In this work it was demonstrated for the first time that vapothermal pre-treatment of the vegetable part of the substrate mix (i.e. the reed grass) prior to anaerobic digestion leads to lower electricity generation costs exceeding a certain plant size; i.e. above a certain threshold the increased biogas yield due to the vapothermal pre-treatment overcompensated the additional expenditure of the treatment. Thereby, it was shown that the thermal energy required for vapothermal pretreatment can be obtained $100 \%$ from the residual heat of the combined heat and power unit (CHP-unit).

However, compared with other purely thermal pre-treatment, the positive effect of vapothermal pre-treatment on the cost of electricity seems to be lower. However, the relative advantage of the different pre-treatment options relative to each other might also be influenced by the feedstock characteristics. In this study, no comparison could be made for identical substrates due to the limited literature data available. It might be possible that the positive effects of the vapothermal pre-treatment are higher for other types of lignocellulosic substrates. Nevertheless, it could be clearly demonstrated that vapothermal pre-treatment is economically superior to other pretreatment processes that require additional chemicals such as acids or bases.

Ultimately, however, it must be noted that if no further resulting advantages are also taken into account, in the geographical regions considered here (i.e. MENA-region), the generation of electricity from biogas as carried out in this study is not yet economic viable compared to an electricity generation via Diesel fuel combustion. In the most favorable case, the corresponding Diesel fuel equivalent price is 1.00 $€ \mathrm{~L}^{-1}$.

Acknowledgements We would like to express our gratitude to BAUER Nimr LCC that supported our work by sharing their experience about constructed wetlands in desert regions.

Author contributions Marvin Scherzinger: Methodology, Formal analysis, Investigation, Writing - Original Draft, Visualization
Martin Kaltschmitt: Supervision

Funding Open Access funding enabled and organized by Projekt DEAL. There was no funding for the present article.

Availability of data and material The authors declare that all data sources have been properly marked. Furthermore, the authors declare that data used during the preparation of the manuscript will be made available on reasonable request.

\section{Declarations}

Conflict of interests The authors declare that there are no conflicts of interest.

Ethical approval The paper reflects the authors' own research and analysis in a truthful and complete manner. Furthermore, the paper does not contain any ethically questionable information, nor were any ethical questionable experiments performed in order to gain the results.

Consent to participate The authors mutually agree that they participated in the preparation of the manuscript.

Consent for publication The authors declare that the manuscript is their intellectual property and that they want to publish it in the Journal "Clean Technologies and Environmental Policy".

Open Access This article is licensed under a Creative Commons Attribution 4.0 International License, which permits use, sharing, adaptation, distribution and reproduction in any medium or format, as long as you give appropriate credit to the original author(s) and the source, provide a link to the Creative Commons licence, and indicate if changes were made. The images or other third party material in this article are included in the article's Creative Commons licence, unless indicated otherwise in a credit line to the material. If material is not included in the article's Creative Commons licence and your intended use is not permitted by statutory regulation or exceeds the permitted use, you will need to obtain permission directly from the copyright holder. To view a copy of this licence, visit http://creativecommons.org/licenses/by/4.0/.

\section{References}

2G Energy AG (2020) agenitor I BHKW 75 bis $450 \mathrm{~kW}$ - 2G. https:// www.2-g.com/de/agenitor-75-bis-450-kw/. Accessed 9 December 2020

Al-Shamma'a AA, Alturki FA, Farh HMH (2020) Techno-economic assessment for energy transition from diesel-based to hybrid energy system-based off-grids in Saudi Arabia. Energy Transit. https://doi.org/10.1007/s41825-020-00021-2

Bacenetti J, Negri M, Fiala M, González-García S (2013) Anaerobic digestion of different feedstocks: impact on energetic and environmental balances of biogas process. Sci Total Environ 463464:541-551. https://doi.org/10.1016/j.scitotenv.2013.06.058

Baetge S, Kaltschmitt M (2018) Rice straw and rice husks as energy sources-comparison of direct combustion and biogas production. Biomass Conv. Bioref. 8:719-737. https://doi.org/10.1007/ s13399-018-0321-y

Baeuerle U (2012) Reinigung von mit Öl verschmutztem Wasser, Erzeugung von Prozesswasser, Erdölförderung und/oder -raffinierung (EP 2730548 A1) 
Baneshi M, Hadianfard F (2016) Techno-economic feasibility of hybrid $\mathrm{diesel} / \mathrm{PV} / \mathrm{wind} /$ battery electricity generation systems for non-residential large electricity consumers under southern Iran climate conditions. Energy Conversion and Management 127:233-244. https://doi.org/10.1016/j.enconman.2016.09.008

BP p.I.c. (2020) Statistical Review of World Energy, London

Bruno JC, Ortega-López V, Coronas A (2009) Integration of absorption cooling systems into micro gas turbine trigeneration systems using biogas: case study of a sewage treatment plant. Applied Energy 86:837-847. https://doi.org/10.1016/j.apenergy.2008.08.007

Dachs G, Rehm W (2006) Der Eigenstromverbrauch von Biogasanlagen und Potenziale zu dessen Reduzierung

Delzeit R, Kellner U (2013) The impact of plant size and location on profitability of biogas plants in Germany under consideration of processing digestates. Biomass and Bioenergy 52:43-53. https:// doi.org/10.1016/j.biombioe.2013.02.029

Duennebeil A (2021) Schlammdichte. http://www.pondus-verfahren. de/tabellen1-schlammdichte-tr-gv.pdf. Accessed 4 June 2021

Edenhofer O, Flachsland C, Arlinghaus J, Haywood L, Kalkuhl M, Knopf B, Koch N, Kornek U, Pahle M, Pietzcker R, Steckel J, Ward H (2018) Eckpunkte einer CO2-Preisreform für Deutschland

FNR (ed) (2011) Einsatz von Hilfsmitteln zur Steigerung der Effizienz und Stabilität des Biogasprozesses

FNR (ed) (2016) Leitfaden Biogas: Von der Gewinnung zur Nutzung, 7 th edn. Fachagentur Nachwachsende Rohstoffe, Gülzow

FNR (2020) FNR - Biogas: Faustzahlen. https://biogas.fnr.de/datenund-fakten/faustzahlen/. Accessed 3 December 2020

FNR (2021) Schilfrohr. https://baustoffe.fnr.de/daemmstoffe/mater ialien/schilfrohr/. Accessed 4 June 2021

Fuebbeker A (2018) Fahrsiloanlagen planen und bauen. https://www. lwk-niedersachsen.de/index.cfm/portal/6/nav/350/article/33475. html. Accessed 3 December 2020

Granéli W (1984) Reed Phragmites australis (Cav.) Trin. ex steudel as an energy source in Sweden. Biomass 4:183-208. https://doi.org/ 10.1016/0144-4565(84)90056-8

Häring G, Sonnleitner M, Zörner W, Brügging E, Bücker C, Wetter C, Vogt R (2010) Handreichung zur Optimierung von Biogasanlagen

Kaltschmitt M, Hartmann H, Hofbauer H (2016) Energie aus Biomasse. Springer, Berlin

Kratky L, Jirout T (2011) Biomass size reduction machines for enhancing biogas production. Chem. Eng. Technol. 34:391-399. https:// doi.org/10.1002/ceat.201000357

Laub K, Ziegler C, Wern B, Porzig M (2015) Alternative Biogasverwertungswege: Teilbericht IV

Lauer M, Leprich U, Thrän D (2020) Economic assessment of flexible power generation from biogas plants in Germany's future electricity system. Renewable Energy 146:1471-1485. https://doi.org/10. 1016/j.renene.2019.06.163

Menardo S, Airoldi G, Balsari P (2012) The effect of particle size and thermal pre-treatment on the methane yield of four agricultural by-products. Bioresour Technol 104:708-714. https://doi.org/10. 1016/j.biortech.2011.10.061

Mirmasoumi S, Khoshbakhti Saray R, Ebrahimi S (2018) Evaluation of thermal pretreatment and digestion temperature rise in a biogas fueled combined cooling, heat, and power system using exergo-economic analysis. Energy Conversion and Management 163:219-238. https://doi.org/10.1016/j.enconman.2018.02.069

MLUK (ed) (2006) Biogas in der Landwirtschaft: Leitfaden für Landwirte und Investoren im Land Brandenburg, 3rd edn.

MWM (2021) Gesenkte Betriebskosten durch reduzierten Schmierölverbrauch von MWM Gasmotoren. https://www.mwm.net/ mwm-kwk-bhkw/presse/pressemitteilungen/gesenkte-betriebsko sten-durch-reduzierten-schmieroelverbrauch-von-mwm-gasmo toren/. Accessed 6 January 2021

Neukirchen F, Ries G (2016) Fossile Energie. In: Neukirchen F, Ries G (eds) Die Welt der Rohstoffe. Springer, Berlin, pp 277-316
Passos F, Ortega V, Donoso-Bravo A (2017) Thermochemical pretreatment and anaerobic digestion of dairy cow manure: experimental and economic evaluation. Bioresour Technol 227:239-246. https://doi.org/10.1016/j.biortech.2016.12.034

Peters MS, Timmerhaus KD, West RE (2003) Plant Design and Economics for Chemical Engineers, 5th edn.

Polster A, Brummack J (2004) Preiswerte Biogasentschwefelung an Sekundärrohstoffen

Qiao W, Peng C, Wang W, Zhang Z (2011) Biogas production from supernatant of hydrothermally treated municipal sludge by upflow anaerobic sludge blanket reactor. Bioresour Technol 102:99049911. https://doi.org/10.1016/j.biortech.2011.08.037

Quicker P, Weber K (eds) (2016) Biokohle. Springer Fachmedien Wiesbaden, Wiesbaden

Rajput AA, Zeshan Visvanathan C (2018) Effect of thermal pretreatment on chemical composition, physical structure and biogas production kinetics of wheat straw. J Environ Manage 221:45-52. https://doi.org/10.1016/j.jenvman.2018.05.011

World Bank Group (ed) (2017) Report of the High-Level Commission on Carbon Prices

Roj-Rojewski S, Wysocka-Czubaszek A, Czubaszek R, Kamocki A, Banaszuk P (2019) Anaerobic digestion of wetland biomass from conservation management for biogas production. Biomass and Bioenergy 122:126-132. https://doi.org/10.1016/j.biombioe.2019. 01.038

Rueckert J (2020) Optimale Fermentation durch Flüssigfütterung. https://www.biogaseffizienz.info/optimierung-und-sanierung/ fluessigfuetterung.php. Accessed 3 December 2020

Scherzinger M, Kaltschmitt M (2021) Thermal pre-treatment options to enhance anaerobic digestibility - A review. Renewable and Sustainable Energy Reviews. https://doi.org/10.1016/j.rser.2020. 110627

Scherzinger M, Kaltschmitt M, Thoma M (2021) Effects of vapothermal pretreatment on anaerobic degradability of common reed. Energy Technol. https://doi.org/10.1002/ente.202001046

Scholwin F, Fritsche WR, Daniel J, Hofmann F, Seiffert M, Fischer, E. Wiegmann, K. (2007) Beurteilung von Biogasanlagenparks im Vergleich zu Hof-Einzelanlagen

Sgroi F, Di Trapani AM, Foderà M, Testa R, Tudisca S (2015) Economic performance of biogas plants using giant reed silage biomass feedstock. Ecolog. Eng 81:481-487. https://doi.org/10. 1016/j.ecoleng.2015.04.068

Shafiei M, Kabir MM, Zilouei H, Sárvári Horváth I, Karimi K (2013) Techno-economical study of biogas production improved by steam explosion pretreatment. Bioresour Technol 148:53-60. https://doi. org/10.1016/j.biortech.2013.08.111

Stefanakis A, Akratos CS, Tsihrintzis VA (2014) Vertical flow constructed wetlands: Eco-engineering systems for wastewater and sludge treatment. Elsevier, Amsterdam

Stephan P, Kabelac S, Kind M, Mewes D, Schaber K, Wetzel T (2019) VDI-Wärmeatlas. Springer, Berlin

Towler G, Sinnot R (2013) Chemical Engineering Design: Principles, Practise and Economics pf Plant and Process Design, 2nd edn. Elsevier

Tribe MA, Alpine R (1986) Scale economies and the "0.6 rule." Eng. Costs Prod. Econom. 4:271-278. https://doi.org/10.1016/S0167188X(86)80025-8

Vogelsang GmbH \& Co. KG (2020) EnergyJet - Feststoffdosierer für abrasive NawaRo. https://www.vogelsang.info/de/produkte/fests toffdosierer/energyjet/. Accessed 3 December 2020

VDI (2012) VDI 6025: Economy calculation systems for capital goods and plants:1-152

Walla C, Schneeberger W (2008) The optimal size for biogas plants. Biomass and Bioenergy 32:551-557. https://doi.org/10.1016/j. biombioe.2007.11.009 
WorldWeatherOnline (2020) Marmul Monthly Climate Averages. https://www.worldweatheronline.com/lang/de/marmul-weatheraverages/zufar/om.aspx. Accessed 28 October 2020

Xiao C, Fu Q, Liao Q, Huang Y, Xia A, Chen H, Zhu X (2020) Life cycle and economic assessments of biogas production from microalgae biomass with hydrothermal pretreatment via anaerobic digestion. Renewable Energy 151:70-78. https://doi.org/10. 1016/j.renene.2019.10.145
Publisher's Note Springer Nature remains neutral with regard to jurisdictional claims in published maps and institutional affiliations. 